\title{
Acute intraoperative brain herniation during elective neurosurgery: pathophysiology and management considerations
}

\author{
Ian $\mathrm{R}$ Whittle, Rajaraman Viswanathan
}

\begin{abstract}
Objectives-To describe operative procedures, pathophysiological events, management strategies, and clinical outcomes after acute intraoperative brain herniation during elective neurosurgery.

Methods-Review of clinical diagnoses, operative events, postoperative CT findings, intracranial pressure, and arterial blood pressure changes and outcomes in a series of patients in whom elective neurosurgery had to be abandoned because of severe brain herniation.

Results-Acute intraoperative brain herniation occurred in seven patients. In each patient subarachnoid or intraventricular haemorrhage preceded the brain herniation. The haemorrhage occurred after intraoperative aneurysm rupture either before arachnoidal dissection (three) or during clip placement (one); after resection of $70 \%$ of a recurrent hemispheric astroblastoma; after resection of a pineal tumour; and after a stereotactic biopsy of an AIDS lesion. In all patients the procedure was abandoned because of loss of access to the intracranial operating site, medical measures to control intracranial pressure undertaken (intravenous thiopentone), an intraventricular catheter or Camino intracranial pressure monitor inserted, and CT performed immediately after scalp closure. The patients were transferred to an intensive care unit for elective ventilation and multimodality physiological monitoring. Using this strategy all patients recovered from the acute ictus and no patient had intracranial pressure $>35 \mathrm{~mm} \mathrm{Hg}$. Although one patient with an aneurysm rebled and died three days later the other six patients did well considering the dramatic and apparently catastrophic nature of the open brain herniation.
\end{abstract}

Department of Clinical Neurosciences, Western General Hospital, Edinburgh EH4 2XU, UK I R Whittle $R$ Viswanathan

Correspondence to: Mr I R Whittle, Department of Clinical Neurosciences Western General Hospita Crewe Road, Edinburgh EH4 2X, UK.

Received 2 June 1995 and in final revised form 29 January 1996 Accepted 9 February 1996 dure and closure of the cranium may also have contributed to the often very satisfactory clinical outcome.

(F Neurol Neurosurg Psychiatry 1996;61:584-590)

Keywords: brain herniation; intraoperative aneurysm rupture; subarachnoid haemorrhage; intraventricular haemorrhage

Profound intraoperative brain swelling and herniation through an elective craniotomy was in most instances, before modern neuroanaesthesia, related to either hypercarbia or to high venous pressures. Nowadays such an event is uncommon and is only occasionally found after evacuation of a post-traumatic acute subdural haematoma. ${ }^{1}$ In this situation the herniation is thought to be related to cerebral vasodilatation and hydrostatic brain oedema secondary to brain decompression ${ }^{2-4}$ and to alterations in the biomechanics of the brain after craniotomy. ${ }^{5}$ Less commonly it may be related to the development of distant intracranial haematomata. ${ }^{6}$

Because profound brain swelling and herniation during elective neurosurgery is infrequently reported we present seven patients, all under the care of the senior author (IRW), in whom such complications occurred. The aims are to clarify the pathophysiological mechanisms underlying such brain swelling and to make certain management recommendations. Pathophysiological mechanisms are implied from observed intraoperative events, immediate postoperative neuroimaging studies, and recording of multiple systemic and neurophysiological variables. Management strategies were based on the principles of providing an optimal systemic and intracranial milieu to minimise secondary brain insults.

\section{Methods}

The case records of seven patients who all developed profound brain herniation during elective neurosurgical procedures were thoroughly reviewed. This cohort comprised about $0.7 \%$ of all cranial procedures performed by the senior author over the time of the study. The clinical and surgical details, preoperative observation charts, intraoperative anaesthetic records, and postoperative intensive care unit records were analysed and all measured physiological variables were plotted on appropriately scaled graphs so the time course of 
changes in these variables could be analysed in relation to the apparently catastrophic intraoperative event. Immediate postsurgical CT radiographs were compared with preoperative studies.

\section{Clinical details}

Three patients had subarachnoid haemorrhage from anterior communicating artery aneurysm rupture and were WFNS grade I or II preoperatively (surgery being performed two, seven, and 11 days after aneurysmal rupture). One patient had subarachnoid haemorrhage from a posterior communicating internal carotid artery aneurysm and was WFNS grade I preoperatively (surgery performed on day 1). One patient had AIDS, toxoplasma retinitis, and intracerebral lesions unresponsive to two weeks of antitoxoplasma treatment. Neurologically he had profound psychomotor slowing but neither features of raised intracranial pressure nor focal neurological deficit. Two others had intracerebral tumours (patient 6 a pineoblastoma and patient 7 a recurrent left temporal astroblastoma) with fixed focal neurological deficits despite preoperative steroid therapy. Neither had impairment of concious state or papilloedema despite hydrocephalus (patient 6) and a large mass lesion (patient 7). Table 1 summarised the clinical features of these patients.

\section{Anaesthetic details}

In all patients endotracheal general anaesthesia was administered by an experienced consultant neuroanaesthetist. Premedication was with $5 \mathrm{mg}$ droperidol and $0.6 \mathrm{mg}$ atropine. Thiopentone and alcuronium were used for induction and anaesthesia was maintained with phenoperidine and nitrous oxide/oxygen mixture $\left(\mathrm{FiO}_{2} 0 \cdot 3\right)$. Neither $\alpha$ nor $\beta$ adrenergic blocking agents were given before or during intubation, induction, or maintanance of anaesthesia. Multiple physiological variables including arterial blood pressure (radial artery line), heart rate, central venous pressure, oxygen saturation $\left(\mathrm{SaO}_{2}\right)$, and end tidal $\mathrm{CO}_{2}$ were continuously monitored throughout the operation. All variables were stable before the acute intraoperative brain swelling.

\section{Operative details}

Patients were positioned supine with the head rotated to one side with the contralateral shoulder raised for aneurysm surgery. The patient undergoing stereotactic biopsy was in the supine position. The patient undergoing pineal surgery was prone, with head slightly extended and rotated to the right. The patient having reoperation for brain tumour was in the lateral position. The Mayfield pin headrest was used for all patients except the stereotactic biopsy. Head up tilt of $15^{\circ}$ was routine. Severe brain herniation ocurred within minutes in every patient. In three patients $(1,2$, and 4$)$ it ocurred after pterional craniotomy (with a free bone flap) and dural opening but before either basal or sylvian fissure arachnoidal dissection. In these patients it was assumed to be due to introperative aneurysmal rupture because of the profuse basal arterial bleeding that accompanied the herniation. In each patient the procedure was abandoned and the scalp was closed in a single layer over the herniating brain. In one patient (4) the free bone flap was left "floating" subcutaneously whereas in the other two patients this was physically impossible. In another patient (3) rupture of the aneurysm ocurred at the time of clip placement and was followed by brain swelling and herniation. However, in this patient definitive aneurysmal clip placement was possible by using temporary anterior cerebral artery clipping before obliteration of the surgical field by the swelling brain. The wound was closed rapidly in a single layer over the herniating brain.

One patient (5), with AIDS and multiple intracerebral lesions, had an uneventful biopsy of a parietal lesion. After a second target in the frontal region was biopsied arterial blood was noted to flow from the biopsy track. It was assumed that a small cortical arteriole at the base of a sulcus was avulsed and rapidly thereafter cerebral tissue herniated (like toothpaste coming out of a tube) through the dural opening and burr hole site. In patient 6 brisk venous bleeding occurred after a $2.5 \mathrm{~cm}$ pineoblastoma had been excised and tumour bed haemostasis obtained. The onset of bleeding followed withdrawal of two microretractors from the deep parafalcine occipital lobe-tentorial region. Initially it was consid-

Table 1 Clinical data in seven patients with severe intraoperative brain hernia

\begin{tabular}{|c|c|c|c|c|c|}
\hline $\begin{array}{l}\text { Patient } \\
\text { No }\end{array}$ & Age/Sex & Diagnosis & Preoperative grade & Procedure & Timing of hernia \\
\hline 1 & $52 / \mathrm{F}$ & \multirow{6}{*}{$\begin{array}{l}\text { L Post Comm A } \\
\text { aneurism } \\
\text { Ant Comm A } \\
\text { aneurysm } \\
\text { Ant Comm A } \\
\text { aneurysm } \\
\text { Ant Comm A } \\
\text { aneurysm } \\
\text { AIDS, cerebral } \\
\text { toxoplasmosis } \\
\text { Pineoblastoma }\end{array}$} & WFNS I & $\begin{array}{l}\text { Pterional } \\
\text { craniotomy }\end{array}$ & \multirow{3}{*}{$\begin{array}{l}\text { After dural opening, } \\
\text { prearachnoid dissection } \\
\text { After dural opening, } \\
\text { prearachnoid dissection } \\
\text { During clip placement }\end{array}$} \\
\hline 2 & $65 / F$ & & WFNS I & $\begin{array}{l}\text { Pterional } \\
\text { craniotomy }\end{array}$ & \\
\hline 3 & $39 / \mathrm{F}$ & & WFNS II & $\begin{array}{l}\text { Pterional } \\
\text { craniotomy }\end{array}$ & \\
\hline 4 & $44 / M$ & & WFNS II & $\begin{array}{l}\text { Pterional } \\
\text { craniotomy }\end{array}$ & \multirow{4}{*}{$\begin{array}{l}\text { After dural opening, } \\
\text { prearachnoid dissection } \\
\text { After biopsy of frontal } \\
\text { (second) lesion } \\
\text { After near total } \\
\text { excision of tumour } \\
\text { After } 70 \% \text { excision of } \\
\text { tumour }\end{array}$} \\
\hline 5 & $41 / \mathrm{M}$ & & $\begin{array}{l}\text { GCS 15, } \\
\text { psychomotor slowing }\end{array}$ & $\begin{array}{l}\text { Stereotactic } \\
\text { biopsy }\end{array}$ & \\
\hline 6 & $39 / F$ & & GCS 15, & $\begin{array}{l}\text { Occipital } \\
\text { craniotomy }\end{array}$ & \\
\hline 7 & $44 / M$ & $\begin{array}{l}\text { Recurrent } \\
\text { astroblastoma }\end{array}$ & $\begin{array}{l}\text { GCS 15, } \\
\text { dysphasia }\end{array}$ & $\begin{array}{l}\text { Temperoparietal } \\
\text { craniotomy }\end{array}$ & \\
\hline
\end{tabular}

$\mathrm{L}=$ left; Ant Comm = anterior communicating; Post Comm = posterior communicating; GCS = Glasgow coma score; WFNS = World Federation of Neurological Surgeons Grading. 
Table 2 Physiological changes and outcome in patients with severe intraoperative brain hernia

\begin{tabular}{|c|c|c|c|c|c|c|c|c|}
\hline \multirow[b]{2}{*}{$\begin{array}{l}\text { Patient } \\
\text { No }\end{array}$} & \multicolumn{3}{|c|}{ Acute changes at the time of hermiation } & \multicolumn{5}{|c|}{ Postoperative findings } \\
\hline & $H R$ & $B P$ & ICP control & Closure & Pupils & $C T$ & $\begin{array}{l}\text { Elective } \\
\text { ventilation }\end{array}$ & Outcome \\
\hline 1 & $60 \rightarrow 45$ & $140 / 90 \rightarrow 200 / 90$ & Thiopentone & SC & PER & $\begin{array}{l}\text { Diffuse } \\
\text { SAH }\end{array}$ & 11 days & $\begin{array}{l}\text { Expressive } \\
\text { aphasia monoparesis }\end{array}$ \\
\hline 2 & $90 \rightarrow 85$ & $140 / 80 \rightarrow 210 / 100$ & $\begin{array}{l}\text { Thiopentone } \\
\text { EVD }\end{array}$ & SC & PER & $\begin{array}{l}\text { Diffuse } \\
\text { SAH; }\end{array}$ & 24 hours & $\begin{array}{l}\text { Rebleed and } \\
\text { death }\end{array}$ \\
\hline 3 & $100 \rightarrow 90$ & $140 / 80 \rightarrow 110 / 90$ & Thiopentone & BFR & PER & $\begin{array}{l}\text { Diffuse } \\
\text { SAH; } \\
\text { IVH }\end{array}$ & 24 hours & Excellent \\
\hline 4 & $80 \rightarrow 100$ & $110 / 80 \rightarrow 130 / 100$ & Thiopentone & SC & Pinpoint & $\begin{array}{l}\text { Diffuse } \\
\text { SAH }\end{array}$ & 72 hours & Excellent \\
\hline 5 & $90 \rightarrow 115$ & $100 / 70 \rightarrow 220 / 150$ & Thiopentone & SC & $\begin{array}{l}\text { Small } \\
\text { unreactive }\end{array}$ & $\begin{array}{l}\text { Diffuse } \\
\text { SAH }\end{array}$ & 24 hours & Death at 10 days \\
\hline 6 & $68 \rightarrow 65$ & $110 / 60 \rightarrow 100 / 60$ & EVD & SC & Pinpoint & $\begin{array}{l}\text { SAH and } \\
\text { IVH }\end{array}$ & 24 hours & Good \\
\hline 7 & $90 \rightarrow 100$ & $100 / 70 \rightarrow 130 / 100$ & Thiopentone & BFR & PER & $\begin{array}{l}\text { SAH and } \\
\text { IVH }\end{array}$ & 24 hours & Good \\
\hline
\end{tabular}

$\mathrm{HR}=$ Heart rate; $\mathrm{BP}=$ blood pressure; $\mathrm{SC}=$ scalp closure; $\mathrm{BFR}=$ bone flap replaced; $\mathrm{EVD}=$ external ventricular drain; $\mathrm{PER}=$ pupils equal and reactive $\mathrm{SAH}=$ subarachnoid haemorrhage; IVH = intraventricular haemorrhage.

Figure 1 Patterns of changes in arterial blood after acute intraoperative brain hermiation during elective neurosurgery. The arrowheads denote onset of swelling. $B P$ range is $50-200 \mathrm{~mm} \mathrm{Hg}$. The units of time intervals denoting intraoperative levels are five minutes and postoperatively 30 minutes. Changes in BP are shown in detail for the first hour after onset of swelling. Only patient 5 had an acute hypertensive episode despite receiving thiopentone. pressure $(B P)$ before and

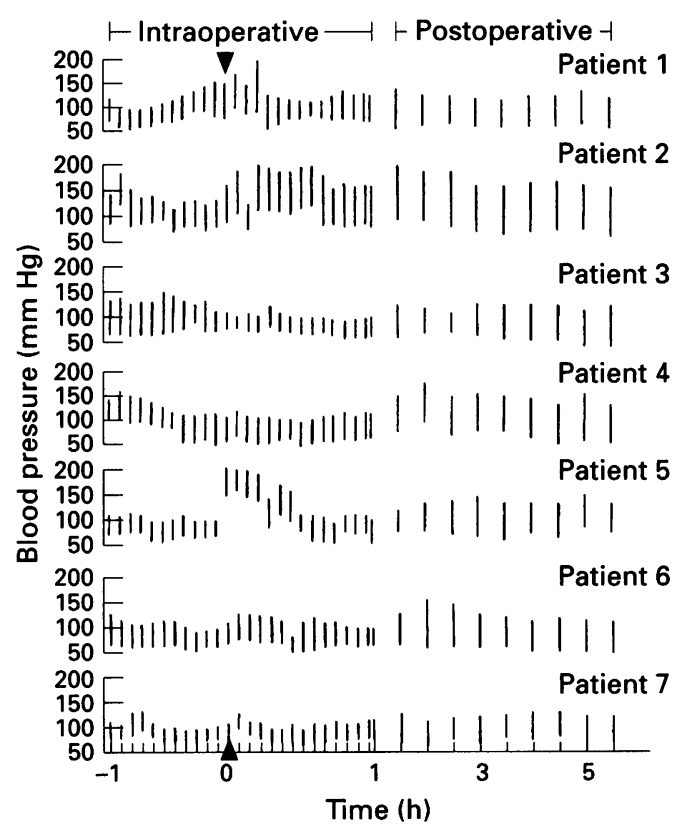

Figure 2 Patterns of postoperative mean intracranial pressure (ICP) in the first six hours after acute intraoperative brain herniation during elective neurosurgery; ICP range in $0-50 \mathrm{~mm} \mathrm{Hg}$ and the units of time intervals are 30 minutes. Patients 1 3 , and 4 had Camino ICP monitors and patients 2 and 6 an intraventricular catheter. Except for patients 1 and 2 mean ICP remained within normal ranges in the early postoperative period.

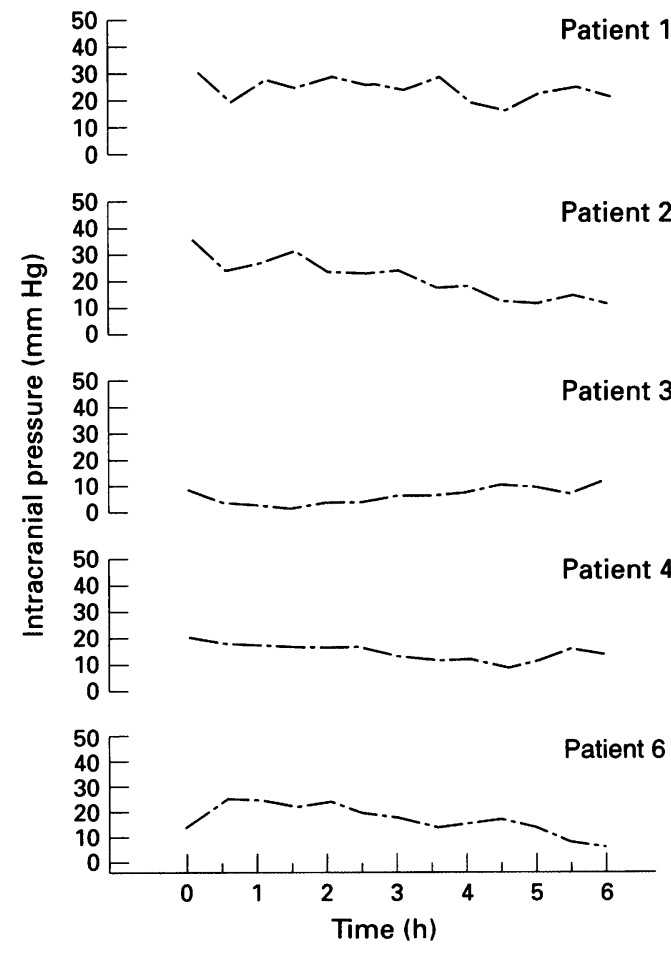

ered that a perigalenic vein had been avulsed. However, the venous haemorrhage was rapidly followed by massive swelling of the occipital lobe through the craniotomy. In this patient the brain swelling was so severe that the occipital pole pia ruptured and clot flowed out of the brain. The scalp was closed in a single layer. It was not possible to even replace the free bone flap in a "floating" fashion. In patient 7, during the later stages of excision of a very vascular recurrent astroblastoma, profuse bleeding from neoplastic arterioles in the periventricular tumour bed resulted in rapid and profound cerebral herniation. Haemostasis and further tumour resection were impossible because the herniating peritumorous brain completely closed access to the surgical field. The scalp was closed over a "floating" bone flap. In none of the seven patients could the dura be closed and manual compression of the scalp flap was required to reduce the brain hernia and enable scalp closure.

\section{Management}

Immediately the brain herniation became apparent a bolus injection of thiopentone, followed by intravenous infusion, was given in every patient. Total thiopentone dose range was $1-5 \mathrm{~g}$ over 0.5 to two hours. There was no obvious immediate benefit in terms of reduction of the brain herniation. Hypotension was not induced in any of our patients nor was mannitol used. After scalp closure all the patients were returned to the adjacent neuroradiology suite under the same anaesthetic and a non-contrast CT was performed. Thereafter a Camino intracranial pressure monitor was placed immediately in three patients $(1,3$, and 4 ) and a ventricular catheter inserted in two patients ( 2 and 6 ). All patients were electively ventilated and medical measures or ventricular drainage was employed to maintain intracranial pressure within normal limits. Mechanical ventilation had to be continued for 11 days in one patient (1) because of pulmonary complications; the other patients were extubated and returned to the neurosurgical ward within three days. 


\section{Figure 3 Matched axial preoperative (right) and postoperative (left) CT of four of the seven patients \\ $(1=A ; 2=B ; 6=C$ $7=D)$. The common \\ features are extensive basal subarachnoid or \\ intraventricula \\ haemorrhage $(C, D)$ and \\ ventricular dilatation. \\ Although both patient 1 \\ and patient 2 had \\ preoperative hydrocephalus \\ both were in good WFNS \\ grade $(A, B)$. The pineal \\ lesion (C) and \\ astroblastoma (D) are \\ obvious in the preoperative scans (arrows).}
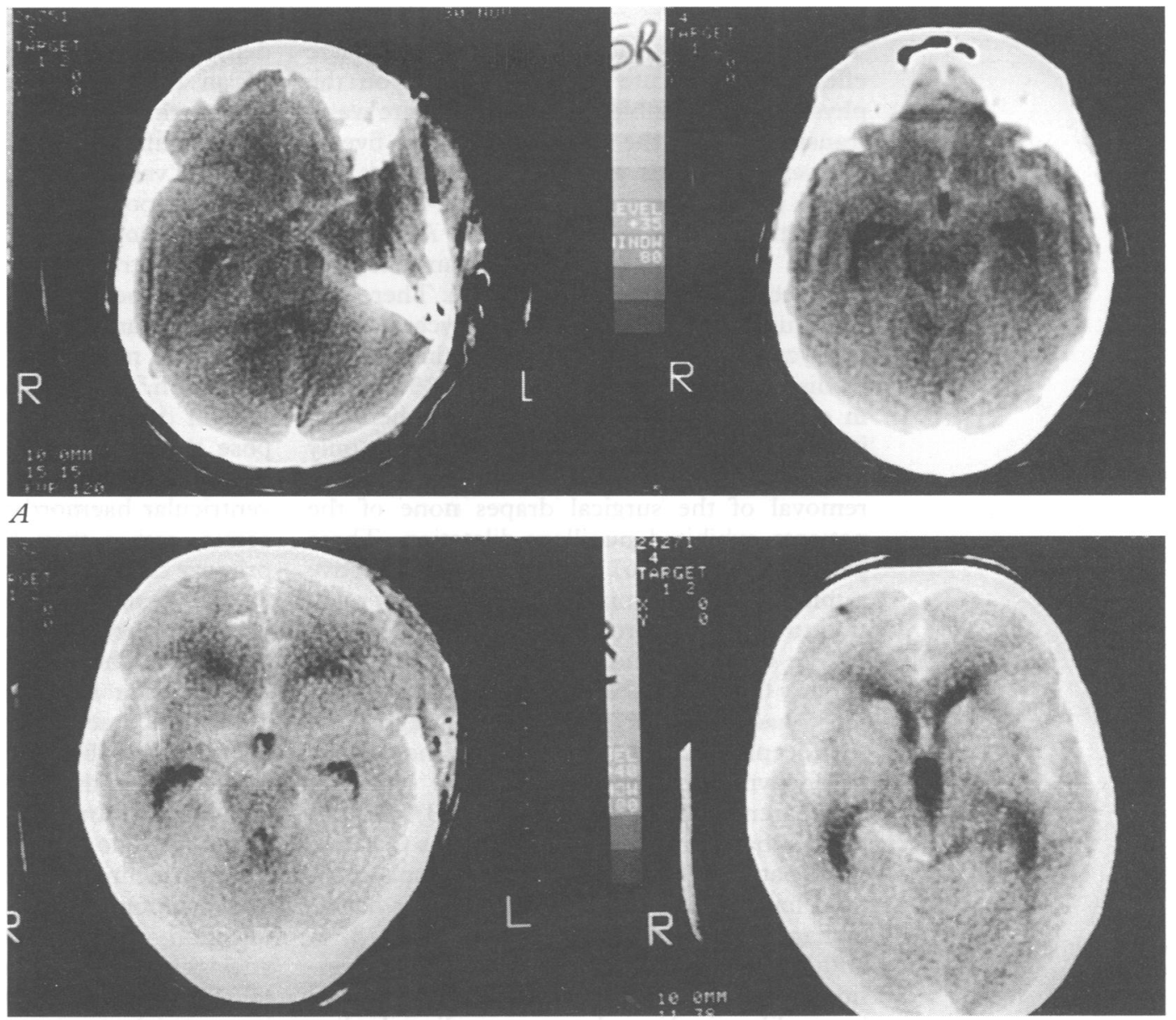

B
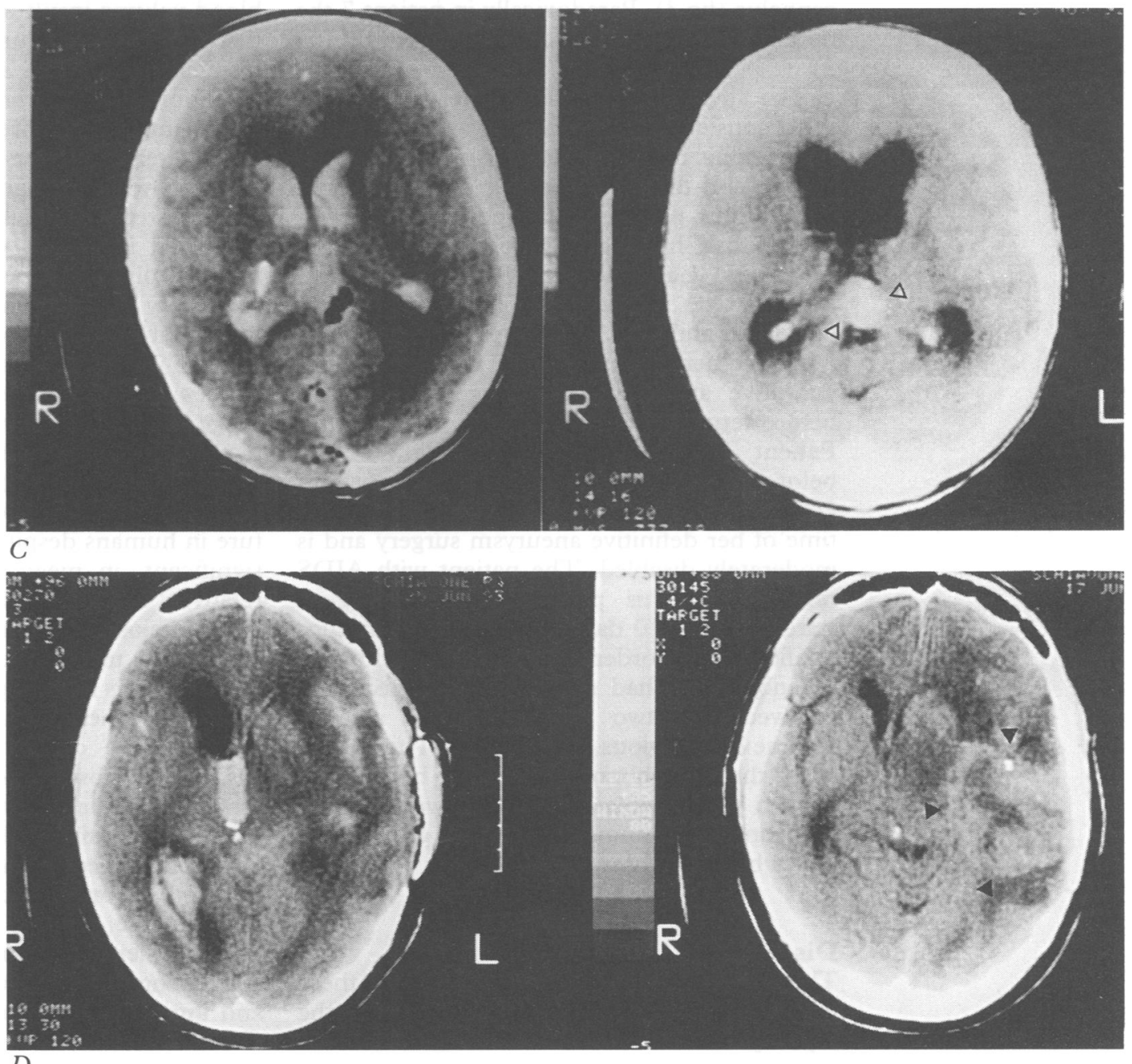


\section{Results}

Table 2 and figs 1 and 2 show the immediate effects of the acute brain herniation on the physiological variables monitored. There was a transient rise in the blood pressure in five of the seven patients and in these patients the blood pressure returned to the pre-event values within 15-30 minutes (fig 1). Alterations in the heart rate were also transient and involved minor fluctuations in rate. There was an equal incidence of mild tachycardia and bradycardia. Intracranial pressure findings (fig 2) disclosed a maximal pressure of $35 \mathrm{~mm} \mathrm{Hg}$ in one patient (2), whereas in the others the intracranial pressure was either normal or only marginally raised (range $8-30 \mathrm{~mm} \mathrm{Hg}$ ). After removal of the surgical drapes none of the patients exhibited pupillary dilatation. Three patients $(4,5$, and 6$)$ had equal but unreactive pupils and in the remainder the pupillary reaction to light was normal.

The common findings on immediate postsurgery CT were subarachnoid or intraventricular haemorrhage with some degree of hydrocephalus. There was minimal intraparenchymal haematoma, midline shift, or intraparenchymal low density (fig 3). Diffuse basal subarachnoid haemorrhage was found in three patients $(1,4$, and 5), whereas subarachnoid haemorrhage and intraventricular haemorrhage were found in four patients $(2,3,6$, and 7). In several patients there was a suggestion of either early hydrocephalus (temporal horn dilatation) or longer standing hydrocephalus (fig 3). Paradoxically in patient 7 the midline shift was less than preoperatively (fig 3).

The overall outcomes were remarkably good considering the dramatic and apparently catastrophic nature of both the open brain herniation and the volume of the acute bleeding. Of the four patients with aneurysms, two (1 and 2) had hemipareses postoperatively; the other two had no lateralising neurological deficit. One patient (2) rebled from her aneurysm and died three days after the intraoperative herniation. One (4) underwent later definitive aneurysmal clipping and excision before returning to his previous employment. Patient 3 also made a complete recovery before returning to work. The fourth patient (1) required duraplasty and cranioplasty at the time of her definitive aneurysm surgery and is moderately disabled. The patient with AIDS recovered to his preoperative neurological state but died 10 days later from his immunodeficiency disorder. The woman with the pineoblastoma had a visual field defect that resolved over two years, and was able to resume her previous employment. The patient with the astroblastoma, which had transformed to a glioblastoma, underwent further excision of his tumour, duraplasty, and cranioplasty but died three months later.

\section{Discussion}

The most important clinical feature in these patients of elective neurosurgery was the rapidity of onset of the brain herniation. In every patient the intraoperative event was sudden, with the brain herniating within minutes of an observed or occult deep intracranial haemorrhage, and the brain having to be manually confined to effect scalp closure. Both cerebral vasodilatation and brain oedema have been proposed as possible mechanisms for rapid development of brain swelling after craniocerebral trauma. ${ }^{34728}$ Cerebral hyperaemia and brain oedema are not mutually exclusive and vascular engorgement that is severe and persistent may result in widespread oedema formation. ${ }^{78}$ In these cases of rapid brain herniation during elective neurosurgery we propose that combinations of acute intracranial hypertention caused by subarachnoid or intraventricular haemorrhage together with hyperaemia, rather than brain oedema, were the primary causes of herniation.

The proposed cerebral hyperaemia and acute "pressure" wave intracranial pressure changes in these patients may have occurred directly as a result of either the acute subarachnoid haemorrhage or intraventricular haemorrhage bolus into the CSF space or indirectly by the subarachnoid haemorrhage activating various neurovascular reflex mechanisms. ${ }^{9-11}$ The first hypothesis would invoke the subarachnoid haemorrhage or intraventricular haemorrhage being envisaged as a bolus injection into the CSF. This would be analagous to performing an acute experimental WITH, the peak and duration of the intracranial pressure wave being related to the blood volume insult into the CSF, the rate of bleeding, and the underlying lumped craniospinal compliance at the time of the subarachnoid or intraventricular haemorrhage. ${ }^{12}$ Acute intracranial pressure "pressure waves" and increases in the cerebral blood volume with or without significant changes in the mean systemic arterial pressure have also been described in several experimental paradigms that involve electrical stimulation of the medullary and pontine nucli. ${ }^{13-15}$ It is postulated that excitation of these regions, perhaps due to brainstem microcirculatory disturbances caused by the subarachnoid haemorrhage, results in neurogenic vasodilation and hyperaemia. ${ }^{16}$ This postulate is consistent with the increases in cerebral blood flow of $46 \%$ recorded after intraoperative aneurysmal rupture in humans despite a decrease, albeit nonsignificant, in mean arterial pressure. ${ }^{22}$ The relative "damping" of any systemic vascular hypertension and absence of any consistent change in mean arterial blood pressure in these patients may be partly attributable to the effects of general anaesthesia. ${ }^{1317}$ The generalised nature of the subarachnoid haemorrhage and absence of midline shift, deep intracerebral haematoma, and either focal or generalised brain oedema on the postoperative CT (performed within 60 minutes of the ictus), the short lived course of raised intracranial pressure, and the apparent benefit of barbiturates lend support to these hypotheses. The changes in the blood pressure, heart rate, and intracranial pressure seen in our patients are similar to those found by Grote and 
Hassler, ${ }^{10}$ Nornes, ${ }^{11}$ and Voldby and Enevoldsen ${ }^{18}$ in patients with subarachnoid haemorrhage although the magnitude of physiological alterations in our series was lower. This is probably related to the fact that our patients had an open craniotomy, thus damping the peaks of the ictal changes. ${ }^{5}$ Studies on experimental subarachnoid haemorrhage have shown a similar course of changes in blood pressure and intracranial pressure ${ }^{919}$ and a possible vascular mechanism for the development of swelling and raised pressure has been shown in dogs. ${ }^{16}$

The remarkable feature of all these patients is that despite an apparently catastrophic intraoperative event all the patients not only survived the acute ictus but-except for the one patient who died in the perioperative period and patient 7, who had a glioblastoma-also recovered to an independent state. These outcomes suggest that the surgeon faced with intraoperative brain herniation complicating occult or overt deep intracranial haemorrhage during elective neurosurgery should not consider either resection of normal brain tissue or induction of systemic hypotension. The first option is not only contrary to basic principles of neurosurgery, but given the fulminant nature of the herniation, it is unlikely that any meaningful surgical resection would have been possible without major loss of neural function. Although brain tissue resection has been performed after rupture of aneurysms before or during dural opening the results are generally very poor. ${ }^{10}$ Farrar et $a l,{ }^{20}$ Gardner, ${ }^{21}$ and Ransohoff and colleagues $^{22}$ suggested the use of systemic hypotension to control intraoperative aneurysmal rupture and reported reasonably favourable results despite the regional cerebral blood flow being at the threshold levels at some sites. However, using such a strategy increases the risk of delayed postopertive ischaemia as aneursymal subarachnoid haemorrhage is generally associated with disordered cerebrovascular reactivity and metabolic activity. ${ }^{21242528}$ Further, in the face of acute brain swelling and raised intracranial pressure both cerebral perfusion pressure and venous drainage may already be compromised in the herniating and retracted brain tissue. Tsementzis and Hitch cock $^{26}$ reported on "rescue clipping" using profound hypotension (MABP $<60 \mathrm{~mm} \mathrm{Hg}$ ) after aneurysmal rupture during induction of anaesthesia. Operative conditions in these patients were poor and $50 \%$ died or were left vegetative. Most surgeons would nowadays generally avoid such levels of hypotension during aneurysmal surgery and if rupture occurred with an open surgical field prefer to rely on temporary clips to obtain haemostasis. ${ }^{2027}$ Certainly in patient 3 temporary occlusion of the anterior cerebral artery retarded the herniation and enabled definitive clipping of an anterior communicating artery.

An important aspect of management in our patients seemed to be closure of the skull and scalp as rapidly as possible. From the relative paucity of intracranial blood seen on the postoperative scans it would seem that re-estab- lishing a "closed cranium" situation is essential in tamponading the source of bleeding ${ }^{11}$ and minimising the risks of secondary venous infarction of the herniating brain. Deleterious effects of continuous open ventricular drainage during subarachnoid haemorrhage such as large intracerebral haematomas and prolonged post-SAH intracranial hypertension have been described. ${ }^{18}$ Furthermore rebound intracranial hypertension after brain compression is not only related to an absolute decrease in the cerebral perfusion pressure below 50 $\mathrm{mm} \mathrm{Hg}$ but also to the duration of circulatory compromise. ${ }^{210}$ Although Batjer and Samson ${ }^{1}$ considered that when faced with profound brain swelling after intraoperative aneursymal rupture, the potential benefits of abandoning the procedure were debatable, ${ }^{20}$ the results from this, albeit small, series would suggest that it may represent a pragmatic approach when the aneurysm has not been exposed. The benefits of expeditious closure of the cranium would also seem supported by the subsequent clinical course of most patients in this series. Replacement of the bone flap, which was physically impossible in several of these patients, does not seem essential for this benefit, although such patients may develop a pseudomeningocele and require later duraplasty and cranioplasty. Multimodality postoperative monitoring is also useful to minimise secondary brain insults and guide when craniospinal dynamics are normalising.

We are indebted to the late Professor JD Miller for his critical comments on the manuscript and Ms J Mason for her typing skills.

1 Lobato RD, Sarabia R, Cordobes F, et al. Post-traumatic cerebral hemisheric swelling. $f$ Neurosurg 1988;68: 417-23.

2 Ishii R. Regional cerebral blood flow in patients with ruptured intracranial aneurysms. F Neurosurg 1979;50: 587-94.

3 Kobrine AI, Kempe LG. Studies in head injury-Part I. An experimental model of closed head injury. Surg Neurol 1973;1:34-7.

4 Langfitt TW, Tannanbaum HM, Kassell NF. The etiology of brain swelling following experimental head injury. $\mathcal{F}$ Neurosurg 1966;24:47-56.

5 Hatashita S, Hoff JT. The effect of craniectomy on the biomechanics of normal brain. F Neurosurg 1987;67:573-8.

6 Meguro K, Kobayashi E, Maki Y. Acute brain swelling during evacuation of subdural hematoma caused by delayed contralateral extradural hematoma: report of two cases. Neurosurgery 1987;20:326-8.

7 Jennett B. Clinical brain swelling: edema or engorgement? In: de Vleiger $M$, de Lange SA, Beks JW, eds Brain edema. New York: John Wiley, 1981:61-5.

8 Miller JD, Corales RL. Brain edema as a result of head injury: fact or fallacy? In: de Vleiger $M$, de Lange SA Beks JW, eds. Brain edema. New York: John Wiley, 1981; 99-115.

9 Dorsch N, Branston N, Symon L, Jakubowsky J. Intracranial pressure in experimental subarachnoid hemorrhage. In: Hoff JT, Betz AL, eds. Intracr

10 Grote E, Hassler W. The critical first minutes after subarachnoid hemorrhage. Neurosurgery 1988;22:654-61.

11 Nornes $H$. The role of intracranial pressure in the arrest of hemorrhage in patients with ruptured intracranial aneurysm. F Neurosurg 1973;39:226-34.

12 Marmarou A, Shulman K, LaMorgese J. Compartmental analysis of compliance and outflow resistance of the cerebrospinal fluid system. $\mathcal{F}$ Neurosurg $1975 ; 48 ; 523-34$.

13 Maeda M, Matsura S. Increase in ICP produced by electrical stimulation of the brain stem reticular formation in cats with spinalization and vagotomy. In: Hoff JT, Betz AL, eds. Intrac

14 Maeda M, Takahashi $\mathrm{K}$, Miyazaki $M$, et al. The role of central monoamine system and cholineceptive pontine area on the oscillation of ICP "pressure waves". In: Miller JD, Teasdale GM, Rowan JO, et al, eds. Intracranial pressure VI. Berlin: Springer Verlag, 1986; 151-5.

15 Nagao S, Nishiura T, Kuyama H, et al. Effect of stimulation of the medullary reticular formation on cerebral vasomotor tonus and intracranial pressure. $\mathcal{f}$ Neurosurg 
$1987 ; 66 ; 548-54$

16 Hashimoto M, Higashi S, Kogure Y, et al. Pressure waves and brain stem microcirculatory disturbance following experimental subarachnoid hemorrhage. In: Hoff $\mathrm{JT}$, Betz AL, eds. Intracranial pressure VII. Berlin: Springer Verlag, 1989: 748-53.

17 Pickard JD, Lovick AHJ, Read DH. Evidence for brain engorgement as the initial cause of brain swelling following noid hemorrhage. Acta Physiol Scand 1986;172(suppl 552):94-5.

18 Voldby B, Enevoldsen EM. Intracranial pressure changes following aneurysm rupture. Part 3: recurrent hemorfollowing aneurysm rupture. Part

19 Trojanowski T. Early effects of experimental subarachnoid hemorrhage on the cerebral circulation: part II. Regional cerebral blood flow and cerebral microcirculation after experimental subarachnoid hemorrhage. Acta Neurochir 1984;72:241-59.

20 Batjer H, Samson D. Intraoperative aneurysmal rupture: incidence, outcome and suggestions for surgical management. Neurosurgery 1986;18:701-1.

21 Farrar JK, Gamache FW, Ferguson GG, Barker J, Varkey GP, Drake CG. Effects of profound hypotension on cerebral blood flow during surgery for intracranial aneurysms. F Neurosurg 1981;55:857-64.
22 Gardner WJ. The control of bleeding during operation by induced hypotension. $\mathcal{F} A M A 1946 ; 132: 572-4$.

23 Ransohoff J, Guy HH, Mazzia VDB, Battista A. Deliberate hypotension in surgery of cerebral aneurysms and correlative animal studies. NY State $\mathcal{f}$ Med 1969;69: 913-8.

24 Pickard JD, Matheson M, Patterson J, Wyper D. Prediction of late ischaemic complications after cerebral aneurysm surgery by the intraoperative measurement of cerebral blood flow. $\mathcal{F}$ Neurosurg 1980;53:305-8.

25 Symon L. Disordered cerbral vascular physiology in aneurysmal subarachnoid hemorrhage. Acta Neurochir 1978;41:7-22.

26 Tsementzis SA, Hitchcock ER Outcome from "rescue clipping" of ruptured intracranial aneurysms during induction anaesthesia and endotracheal intubation. $\mathcal{f}$ Neurol Neurosurg Psychiatry 1985;48:160-3.

27 Suzuki J, Yoshimoto T. The effect of mannitol in prolongation of permissible occlusion time of cerebral arteries: clinical data of aneurysm surgery. In: Suzuki J, ed. Cerebral aneurysms. Tokyo: Neuron Publishing Co, 1979 330-7.

28 Jakobsson K E, Lofgren J, Zwetnow N N. Critical thresholds of rebound of ICP after cerebral compression. In: Hoff JT, Betz AL, eds. Intracranial pressure VII. Berlin: Springer Verlag, 1989:853-7. 